\title{
Current situation of medication errors in Saudi Arabia: a nationwide observational study
}

Thamir M Alshammari ( $\nabla$ Thamer.alshammary@gmail.com )

Saudi Food and Drug Authority https://orcid.org/0000-0002-5630-2468

Khalidah A. Alenzi

Saudi Arabia Ministry of Health

Yasser M Alatawi

University of Tabouk

Afnan S. Almordi

Saudi Arabia Ministry of Health

Ali F. Altebainawi

Saudi Arabia Ministry of Health

Research article

Keywords: Contributing factors, Decision-makers, Dispensing error, Medication errors, Prescribing error

Posted Date: August 27th, 2020

DOI: https://doi.org/10.21203/rs.3.rs-55365/v1

License: (c) (i) This work is licensed under a Creative Commons Attribution 4.0 International License. Read Full License

Version of Record: A version of this preprint was published at Journal of Patient Safety on March 24th, 2021. See the published version at https://doi.org/10.1097/PTS.0000000000000839. 


\section{Abstract}

Background

Medication process complexity could cause confusion among healthcare professionals (HCPs) and patients and lead to medication errors. This nationwide study aimed to characterize the types of medication errors and determine the error occurs in different stages of the medication process.

Methods

This was a retrospective observational study of medication errors reported by 265 government hospitals and primary care centers during the period of March 2018 to June 2019. The reported information include several aspects of medication errors, including patient information, medication information, error information, and the level of staff reporting and causing the error. The medication use process was categorized into ordering/prescribing, transcribing, dispensing, administering, and monitoring.

Results

A total of 71,332 medication error reports were reported between March 2018 and June 2019. The reported errors involved patients aged <10 (12,1312; 17.3\%) and $>60(8,857 ; 12.4 \%)$ years, and the medication error rate was estimated to be $0.15 \%$. Errors were frequently made by physicians $63120(88.5 \%)$ and frequently detected by pharmacists $(75.9 \%)$. The majority of errors were detected at the prescribing stage ( $84.8 \%)$, followed by the transcribing (5.8\%) and dispensing (5.7\%) stages. A total of 4,182 (5.8\%) errors reached the patient. Work overload of staff was associated with one-third of the reported errors (31.6\%), and $22.7 \%$ of the errors were due to a lack of experience among HCPs.

Conclusions

The study highlights the concern regarding medication errors occurrence during different medication use process. Despite all efforts, prescribing stage is still a big concern as source of harm to the patients.

\section{Background}

Medication is an integral part of the management and treatment of many health conditions. However, with an increase in medication use comes a potential risk of harm, which is compounded by the increased use of multiple medications to treat various complex medical conditions, especially in older adults. Furthermore, preventable adverse events (AEs) associated with medications have been considered the main cause of harm in hospitalized patients [1]. Among these patients, and the rate of incidence of AEs has been reported to be between $3 \%$ and $17 \%$ [2-4].

In the United Kingdom, a significant number of AEs were reported to occur due to medication errors, which led to injury in 2-15\% of patients admitted to hospitals [2]. Fortunately, medication errors are considered the most preventable causes of patient harm [2,5]. According to the National Health Service (NHS), the estimated avoidable costs of ADR are $£ 98.5$ million annually, and ADR causes 712 deaths, contributes to 1,708 deaths and consumes 181,626 bed days [6].

The medication use process is complex, involving multiple steps and a variety of personnel [7]. Although errors can occur at each step of the medicationmanagement process, a large number of errors occur during medication administration [8]. In fact, the majority of medication errors involve either administration at an incorrect time (50\%) or dose omissions (42\%). [9] In the United Kingdom, the National Patient Safety Agency reported that approximately $50 \%$ of all errors are related to drug administration [10]. Furthermore, medication administration errors account for 5-20\% of all medication errors in the United States. It has been estimated that these errors cost the US healthcare system approximately \$380 million and harm at least 1.5 million patients annually [11].

The release of the Institute of Medicine's report "To Err is Human" brought attention to the problem of medical errors and sparked a debate about how best to reduce them [12]. This debate initially focused more on reactive methods, such as error reporting, than on proactive methods, such as a good system design [13]. Thus, error- or event-reporting systems initially received the most attention and funding. Even the most recent report by the Institute of Medicine on patient safety heavily focused on reporting systems [14], despite research over the past decade showing that hospital personnel did not report errors in general and that only $5 \%$ of significant errors were reported [15]. In Saudi Arabia, few studies have examined the reporting pattern of medication errors among healthcare providers. One study found that $44.8 \%$ of healthcare practitioners never reported medication errors [16].

Saudi Arabia currently has a public and private healthcare system. Currently, the Ministry of Health is the country's leading healthcare provider, overseeing a total of 282 hospitals ( 43,080 beds) and 2,361 primary healthcare centers. The ministry provides approximately $60 \%$ of the total healthcare services offered to citizens and residents of the country [17]. One of the main goals of the ministry is to improve patient safety by gathering more information about medication errors, maintaining a database of these errors to analyze the contributing factors associated with these errors, and utilizing the data to establish strategies to reduce the incidence of medication errors.

To understand the extent of medication errors in Saudi Arabia, we intended to assess medication errors reported to the General Department of Pharmaceutical Care of the Ministry of Health of Saudi Arabia. Specifically, our aims were to characterize the types of errors and to determine the stages of the medication process in which the errors occurred. In addition, we aimed to identify the groups of healthcare providers who detected and reported errors as well as the potential causes of the errors and the classes of medication involved.

\section{Methods}




\section{Study design and data source}

This was a retrospective observational study of electronic medication errors reported to the General Department of Pharmaceutical Care of the Ministry of Health of Saudi Arabia. The electronic medication error database was structured based on the United States National Coordinating Council (NCC) for Medication Error Reporting and Prevention (MERP) taxonomy of errors. The database comprised medication error reports from 265 government hospitals and primary care centers for the period of March 2018 to June 2019.

\section{The Minsistry of Health medication error reporting system}

The process by which medical staff report medication errors after the discovery of these errors includes the following: 1) completing the paper-based reporting form, 2) sending the form to a medication safety officer within 24 hours, and 3) assessing the event and conducting a root cause analysis. A medication safety officer records the error on the website of the General Department of Pharmaceutical Care of the Ministry of Health. The system aims to collect complete information regarding all aspects of medication errors, including patient information (e.g., sex and age), medication information (i.e., drug name, drug class, route of administration, and dosage form), error information (i.e., date, description of the error, and contributing factors), and the job level of staff reporting and causing the error. Error reporting is voluntary and can be completed by any medical staff member. The NCC MERP defines a medication error as follows: "A medication error is any preventable event that may cause or lead to inappropriate medication use or patient harm while the medication is in the control of the healthcare professional, patient, or consumer. Such events may be related to professional practice, healthcare products, procedures, and systems, including prescribing; order communication; product labeling, packaging, and nomenclature; compounding; dispensing; distribution; administration; education; monitoring; and use". [18].

\section{Statistical analysis}

The data were summarized using frequencies and percentages. The overall medication error rate was computed by dividing the number of errors reported by the total number of prescriptions. The medication error rate of each medication use process was determined by dividing the total number of medication errors in each category by the total number of medication errors reported. The medication use process was categorized into ordering/prescribing, transcribing, dispensing, administering, and monitoring. We further recorded each error based on NCC MERP categories for medication errors. The NCC MERP categories range from " $A$ " to "I," where A represents an event that has the potential to cause harm, " $B$ " to " $D$ " represent an error that did not result in harm, " $E$ " to " $H$ " represent an error that resulted in patient harm, and "I" represents an error that was linked to patient death. The data were managed and analyzed by Statistical Analysis Software, version 9.4.

\section{Results}

The database search from March 2018 to June 2019 revealed a total of 71,332 medication errors. The reported errors frequently involved patients aged < 10 $(12,1312 ; 17.3 \%)$ and $>60(8,857 ; 12.4 \%)$ years (Fig. 1). The amount of drugs dispensed during the study period was estimated to accurately estimate the error rate. It was found that approximately 168 hospitals (59.5\%) used electronic medical records in whole or in part, such as using a computerized prescribing system alone. In addition, automated dispensing systems were used in 175 hospitals, and one pharmacy used an outpatient automated robotic dispensing system. Furthermore, computerized decision support systems (CDSSs) existed only in medical cities. According to information taken from the Statistics Department at the Ministry of Health, a total of $46,437,168$ items were dispensed during the study period. The medication error rate was estimated to be $0.15 \%$. The errors were most frequently made by physicians 63120 (88.5\%) and most frequently detected by pharmacists (75.9\%) (Fig. 2). The majority of errors were detected at the prescribing stage (84.8\%), followed by the transcribing (5.8\%) and dispensing (5.7\%) stages (Table 1$)$.

Table 1 Reported errors by medication use process

\begin{tabular}{|lll|}
\hline Medication process & Frequency & Percentage \\
\hline Prescribing & 60471 & 84.8 \\
\hline Transcribing & 4112 & 5.8 \\
\hline Preparation \& Dispensing & 4472 & 6.2 \\
\hline Administration & 1833 & 2.6 \\
\hline Monitoring & 444 & 0.6 \\
\hline
\end{tabular}

Based on the NCC MERP categories for medication errors, the majority of errors reported were categorized either as an error with the capacity to cause harm (category A, 21.8\%) or an error that occurred but did not reach the patient (category B, 66.3\%) (Table 2). A total of 4,182 (5.8\%) errors reached the patient. Out of the 4,182 reported errors that reached the patient, 3,621 (86.5\%) were categorized as errors that reached the patient but did not cause any harm (category C). Approximately $6.8 \%$ of the reported errors were associated with patient harm. 


\begin{tabular}{|c|c|c|c|}
\hline $\begin{array}{l}\text { Clinical } \\
\text { outcomes }\end{array}$ & & Frequency & Percentage \\
\hline Category A & Circumstances or events that have the capacity to cause errors & 19838 & 21.8 \\
\hline Category B & An error occurred but the error did not reach the patient & 47312 & 66.3 \\
\hline Category C & An error occurred that reached the patient but did not cause harm & 3621 & 5.1 \\
\hline Category D & $\begin{array}{l}\text { An error occurred that reached the patient and required monitoring to confirm that it resulted in no harm to the } \\
\text { patient and/or required intervention to preclude harm }\end{array}$ & 450 & 0.6 \\
\hline Category E & $\begin{array}{l}\text { An error occurred that may have contributed to or resulted in temporary harm to the patient and required } \\
\text { intervention }\end{array}$ & 63 & 0.09 \\
\hline Category F & $\begin{array}{l}\text { An error occurred that may have contributed to or resulted in temporary harm to the patient and required initial } \\
\text { or prolonged hospitalization }\end{array}$ & 23 & 0.03 \\
\hline Category G & An error occurred that may have contributed to or resulted in permanent patient harm & 6 & 0.008 \\
\hline Category H & An error occurred that required intervention necessary to sustain life & 8 & 0.01 \\
\hline Category I & An error occurred that may have contributed to or resulted in the patient's death & 11 & 0.02 \\
\hline
\end{tabular}

(Table 3) shows the possible contributing factors for medication errors encountered in the hospitals/primary care centers included in this study. Work overload of the staff was associated with one-third of the reported errors (31.6\%). Other frequent causes of the medication errors reported were inexperienced health personnel (22.7\%), non-adherence to standard operating procedures (14.8\%), lack of policy (14.3\%), and illegible prescriptions (12.7\%).

Table 3

Reported medication errors by drug class and route of drug administration

\begin{tabular}{|c|c|c|c|}
\hline & & Frequency & Percentage \\
\hline \multirow[t]{5}{*}{ Route of Administration } & Oral & 40328 & 56.5 \\
\hline & Injectable (IV/IM/IT/SC) & 23009 & 32.3 \\
\hline & Inhalation/aerosol & 3204 & 4.5 \\
\hline & Topical Skin/ rectal & 3024 & 4.2 \\
\hline & Eye/ear/nasal & 1767 & 2.5 \\
\hline \multirow[t]{15}{*}{ Drug class } & Antimicrobial & 10024 & 14.0 \\
\hline & Analgesic & 6743 & 9.4 \\
\hline & Hematinic & 6048 & 8.4 \\
\hline & Cardiovascular & 5150 & 7.2 \\
\hline & Neuralgic & 4001 & 5.6 \\
\hline & Gastrointestinal & 3941 & 5.5 \\
\hline & Endocrine & 2803 & 3.9 \\
\hline & Respiratory & 1146 & 1.6 \\
\hline & Other & 834 & 1.1 \\
\hline & Antipsychotic & 170 & 0.239 \\
\hline & Dermatological & 166 & 0.232 \\
\hline & Ophthalmic & 92 & 0.12 \\
\hline & Reproductive & 76 & 0.1 \\
\hline & Chemotherapy & 15 & 0.02 \\
\hline & Unspecified & 30123 & 42.2 \\
\hline
\end{tabular}

(Table 4) shows the frequencies of medication errors with regard to the drug classes and route of administration. The oral route was most frequently associated with medication errors, accounting for 40,328 (56.5\%) of the total errors reported, followed by the injectable route, accounting for 23,009 ( $32.3 \%$ ). Antimicrobials were the drugs with the most medication errors, 10,024 (24.32\%), followed by analgesic drugs, 6,743 (16.4\%), hematinic drugs, 6,048 (14.7\%), and cardiovascular drugs, 5,150 (12.5\%) (Table 4). 
Table 4

Possible causes of medication errors and contributed factors

\begin{tabular}{|lll|}
\hline Possible causes of medication error & Frequency & Percentage \\
\hline Lack of policy & 10201 & 14.3 \\
\hline Inexperienced Personnel & 16200 & 22.7 \\
\hline Sound-alike medication & 963 & 1.4 \\
\hline Look alike medication/ packaging & 825 & 1.2 \\
\hline Illegible prescription & 9072 & 12.7 \\
\hline Wrong labelling/ instruction on dispensing envelope or bottle/container & 1445 & 2.0 \\
\hline Failure to adhere to work procedure & 10536 & 14.8 \\
\hline High workload & 22511 & 31.6 \\
\hline Patient information/ record unavailable/ inaccurate & 3998 & 5.6 \\
\hline Stock arrangement/ storage problem & 470 & 0.7 \\
\hline Not specified & 7681 & 15.8 \\
\hline
\end{tabular}

\section{Discussion}

A medication error report is a valuable source for identifying healthcare system problems, generating solutions, and implementing corrective measures that will ultimately reduce the recurrence of errors. In this study, we evaluated medication errors reported over a 16-month period from a large national electronic database that collects information from over 265 hospitals and primary care centers around the country. We found that the medication error rate was $0.15 \%$, which is very low compared to the $3 \%$ and $6.9 \%$ rates reported in the United Kingdom and United States, respectively [19]. However, the low reporting rate was similar to that reported in another study (0.4\%) conducted in a teaching hospital in Saudi Arabia [20]. Although the Ministry of Health adopts a no-blame culture regarding medication errors and reporting lacks any identifiable information regarding who was responsible for the errors, underreporting remains a major issue. Reporting can be improved by simplifying reporting procedures, increasing awareness, and improving communication between hospital administration staff [21].

This study also found that a large proportion of errors involved pediatric and elderly patients. One study in Saudi Arabia found that $78.8 \%$ of medication errors in pediatric patients were categorized as potentially harmful. This figure was higher than figures in other studies that investigated medication errors in pediatric patients in the US. Further, elderly patients are more prone to medication errors than others because $85-90 \%$ of them use at least one medication [22]. In fact, it has been reported that $30 \%$ of hospital admissions for elderly patients are attributable to medications [23]. Further exploration of the potential causes and contributing factors of errors in pediatric and elderly patients is needed.

This study also found that the majority of errors occurred in the prescribing stage (84.8\%). This finding was similar to that reported in another study conducted in Saudi Arabia, which reported that $89 \%$ of errors were associated with prescribing. Two systematic reviews reported on the rates of prescribing errors, and both studies found that inconsistency in study design and data collection resulted in variations in the error rates reported [24, 25]. However, in a review of 65 studies, the median prescribing error rate was found to be 7\% [24]. Another study found that pharmacists intercepted approximately $75.9 \%$ of errors. The role of pharmacists has been shown to be critical in reducing medication errors. For instance, a meta-analysis of 13 studies found that pharmacist intervention led to a $37 \%$ reduction in medication errors [26].

The present study found that the majority of errors involved the wrong dosage (31.9\%), the wrong medication (13.7\%) and the wrong medication administration (11.1\%). Furthermore, antimicrobial agents (24.3\%) ranked the highest in terms of causing errors, followed by analgasic drugs (16.4\%) and hematological drugs (14.7\%). Our results are similar to those of a study performed by Patel et al., who found that antimicrobial agents were the group of medications that caused the most errors in their study [27].

Regarding the frequency of medications involved in reported errors, the highest frequency was found with paracetamol, vitamin D3, omeprazole, and cefuroxime, which were responsible for $6.2 \%, 3 \%, 2.8 \%$, and $2.1 \%$ of errors, respectively.

The factors contributing to medication errors are numerous; however, human factors are usually involved. We found that workload (31.6\%), inexperienced personnel (22.7\%), failure to adhere to work procedures (14.8\%), lack of policy (14.3\%) and illegible prescriptions (12.7\%) were the major causes of medication errors. One study in Saudi Arabia found that the main causes of medication error were lack of education (67.47\%) and miscommunication (19.04\%), followed by confusion of medications that look and sound alike (7.54\%) [28]. Consistent reliance on humans to perform accurately all the time is unrealistic. A system that relies more on human performance is more likely to fail than a system designed with a greater reliance on well-defined policies and processes. Evidence suggests that human-related errors can be minimized through automation and the implementation of forcing function strategies [28]. For instance,

computerized physician order entry (CPOE) reduced prescribing errors related to drug dosing by $65 \%$, errors due to drug allergies by $56 \%$ and errors due to drug interaction by $54 \%$. CPOE improves patient safety by unifying medication orders, reducing verbal orders and reducing illegibility in prescriptions [29]. Moreover, the CDSSs such as the A dosing support system for common medicines when integrated with CPOE led to a reduction of 16.4 errors per 100 orders. CDSSs help prescribers in therapeutic decision making, dose calclation, duration therapy, and determinations of interactions with drugs or food [30]. 
The implementation of electronic health technology reduces medication errors, but this technology may contribute to errors, especially in the first year of its use [31]. A total of 120 sentinel events were reported to the joint commission related to health information technology between 2010 and June 2013 , and $33 \%$ of the majority errors were seen in the area of human-computer interface [32].

In July 2019 , the Ministry of Health launched an initiative to develop a strategy aiming to resolve the problem of the low number of reports sent by hospitals in several ways: a) facilitating an electronic form and making it available to all health care providers, b) developing a job description for medication safety officers, c) measuring performance monthly by identifying the errors per 1000 items, and d) creating unified guidelines for the medication error reporting system.

Further research is needed to improve the reporting of medication errors, since we found a low reporting rate. The majority of factors contributing to medication errors are human-related, such as increased workload and non-compliance with policy and procedure. More research is also needed to determine suitable strategies to prevent such errors. It is important that we focus on improving our understanding of the scope and nature of errors and implement policies and procedures that will improve patient safety.

Our study has several advantages and limitations. It is the first medication error study at the nationwide level, and it represents all regions in Saudi Arabia. Furthermore, it has a relatively low number of medication errors. However, the current study is limited in that it is descriptive in nature, and we did not analytically evaluate medication errors.

\section{Conclusions}

This nationwide study strresed out a major the concern regarding medication errors. Especially the errors occureed during different medication use process. Presciring error is constitute the highest source of medication errors despite all efforts to reduce this stage in specific. Therefore, a needy efforts by all stakeholders (i.e., health authorities, healtchcare professionals and hospitals) should be implaced to develop more useful strategies to prevent medication errors.

\section{Declarations}

\section{Ethics approval}

The study was approved by Gebenral Direoctrate of Health Affairs, Tabuk Region, Ministry of Health institutional review board “IRB” (IRB protocol No. TU077/019/022). There was no personal or identifiable details are exist in the data.

\section{Acknowledgements}

The authors would like to thank the General Department of Pharmaceutical Care at the Saudi Ministry of Health for providing the data.

\section{Conflict of interest}

Authors have no conflict of interests to disclose.

\section{Funding}

None.

\section{Authors' contribuitons}

TM convinced the idea, designed and conducted the study, wrote and manuscript and supervised the study.

KA played a role in the analyses and writing the manuscript .

YA played role in the methods part and writing the manuscript.

AA played role in the literature review and expert in the data.

AF played role in the methods part and writing the manuscript.

TM finalized the manuscript, which ws susequently approved by all of the authors. Al authors read and approved the final manuscript.

\section{Data availability}

The datasets used and/or analyzed during the current study are available from the corresponidng author upon reasnabole request.

\section{References}

1. Kongkaew C, Hann M, Mandal J, Williams SD, Metcalfe D, Noyce PR, Ashcroft DM: Risk factors for hospital admissions associated with adverse drug events. Pharmacotherapy 2013, 33(8):827-837.

2. Vincent C, Neale G, Woloshynowych M: Adverse events in British hospitals: preliminary retrospective record review. BMJ 2001, 322(7285):517-519. 
3. Baker GR, Norton PG, Flintoft V, Blais R, Brown A, Cox J, Etchells E, Ghali WA, Hebert P, Majumdar SR et al: The Canadian Adverse Events Study: the incidence of adverse events among hospital patients in Canada. CMAJ 2004, 170(11):1678-1686.

4. Thomas EJ, Studdert DM, Runciman WB, Webb RK, Sexton EJ, Wilson RM, Gibberd RW, Harrison BT, Brennan TA: A comparison of iatrogenic injury studies in Australia and the USA. I: Context, methods, casemix, population, patient and hospital characteristics. Int J Qual Health Care 2000, 12(5):371-378.

5. Shaw R, Drever F, Hughes H, Osborn S, Williams S: Adverse events and near miss reporting in the NHS. Qual Saf Health Care 2005, 14(4):279-283.

6. National Study on Hospitalisation-Related Adverse Events. ENEAS 2005.

[https://www.seguridaddelpaciente.es/resources/contenidos/english2/2006/ENEAS_ENG.pdf]

7. Barker KN, Flynn EA, Pepper GA, Bates DW, Mikeal RL: Medication errors observed in $\mathbf{3 6}$ health care facilities. Arch Intern Med 2002, 162(16):1897-1903.

8. Ligi I, Arnaud F, Jouve E, Tardieu S, Sambuc R, Simeoni U: latrogenic events in admitted neonates: a prospective cohort study. Lancet 2008, 371(9610):404-410.

9. Fontan JE, Maneglier V, Nguyen VX, Loirat C, Brion F: Medication errors in hospitals: computerized unit dose drug dispensing system versus ward stock distribution system. Pharm World Sci 2003, 25(3):112-117.

10. The Fourth Report from the Patient Safety Observatory. Safety in doses: medication safety incidents in the NHS [http://data.parliament.uk/DepositedPapers/Files/DEP2008-1788/DEP2008-1788.pdf]

11. Institute of Medicine. 2007. Preventing Medication Errors. Washington, DC: The National Academies Press. https://doi.org/10.17226/11623.

12. . In: To Err is Human: Building a Safer Health System. edn. Edited by Kohn LT, Corrigan JM, Donaldson MS. Washington (DC); 2000.

13. Layde PM, Cortes LM, Teret SP, Brasel KJ, Kuhn EM, Mercy JA, Hargarten SW: Patient safety efforts should focus on medical injuries. JAMA 2002, 287(15):1993-1997.

14. Institute of Medicine. 2004. Patient Safety: Achieving a New Standard for Care. Washington, DC: The National Academies Press. https://doi.org/10.17226/10863.

15. Leape LL, Bates DW, Cullen DJ, Cooper J, Demonaco HJ, Gallivan T, Hallisey R, Ives J, Laird N, Laffel G et al: Systems analysis of adverse drug events. ADE Prevention Study Group. JAMA 1995, 274(1):35-43.

16. Alsulami SL, Sardidi HO, Almuzaini RS, Alsaif MA, Almuzaini HS, Moukaddem AK, Kharal MS: Knowledge, attitude and practice on medication error reporting among health practitioners in a tertiary care setting in Saudi Arabia. Saudi Med J 2019, 40(3):246-251.

17. Saudi Ministry of Health. Statistics and Indicators. Statistical Yearbook (2017) [https://www.moh.gov.sa/en/Ministry/Statistics/book/Pages/default.aspx]

18. National Coordinating Council for Medication Error Reporting and Prevention. [https://www.nccmerp.org/]

19. Dean BS, Allan EL, Barber ND, Barker KN: Comparison of medication errors in an American and a British hospital. Am J Health Syst Pharm 1995, 52(22):2543-2549.

20. Alshaikh M, Mayet A, Aljadhey H: Medication error reporting in a university teaching hospital in Saudi Arabia. J Patient Saf 2013, 9(3):145-149.

21. Hartnell N, MacKinnon N, Sketris I, Fleming M: Identifying, understanding and overcoming barriers to medication error reporting in hospitals: a focus group study. BMJ Qual Saf 2012, 21(5):361-368.

22. Barat I, Andreasen F, Damsgaard EM: The consumption of drugs by 75-year-old individuals living in their own homes. Eur J Clin Pharmacol 2000, 56(67):501-509.

23. Hanlon JT, Schmader KE, Koronkowski MJ, Weinberger M, Landsman PB, Samsa GP, Lewis IK: Adverse drug events in high risk older outpatients. J Am Geriatr Soc 1997, 45(8):945-948

24. Lewis PJ, Dornan T, Taylor D, Tully MP, Wass V, Ashcroft DM: Prevalence, incidence and nature of prescribing errors in hospital inpatients: a systematic review. Drug Saf 2009, 32(5):379-389.

25. Ross S, Bond C, Rothnie H, Thomas S, Macleod MJ: What is the scale of prescribing errors committed by junior doctors? A systematic review. Br J Clin Pharmacol 2009, 67(6):629-640.

26. De Oliveira GS, Jr., Castro-Alves LJ, Kendall MC, McCarthy R: Effectiveness of Pharmacist Intervention to Reduce Medication Errors and Health-Care Resources Utilization After Transitions of Care: A Meta-analysis of Randomized Controlled Trials. J Patient Saf 2017.

27. Patel N, Desai M, Shah S, Patel P, Gandhi A: A study of medication errors in a tertiary care hospital. Perspect Clin Res 2016, 7(4):168-173.

28. Etchells E, Juurlink D, Levinson W: Medication errors: the human factor. CMAJ 2008, 178(1):63-64.

29. Peikari HR, Zakaria MS, Yasin NM, Shah MH, Elhissi A: Role of computerized physician order entry usability in the reduction of prescribing errors. Healthc Inform Res 2013, 19(2):93-101.

30. Sard BE, Walsh KE, Doros G, Hannon M, Moschetti W, Bauchner H: Retrospective evaluation of a computerized physician order entry adaptation to prevent prescribing errors in a pediatric emergency department. Pediatrics 2008, 122(4):782-787.

31. Liao TV, Rabinovich M, Abraham P, Perez S, DiPlotti C, Han JE, Martin GS, Honig E. Evaluation of medication errors with implementation of electronic health record technology in the medical intensive care unit. Open Access Journal of Clinical Trials. 2017;9:31-40.

32. The Joint Commission. Safe use of health information technology. Sentinel Event Alert (42). [https://www.jointcommission.org/-/media/deprecatedunorganized/imported-assets/tjc/system-folders/topics-library/sea_54pdf.pdf?

$\mathrm{db}=$ web\&hash=A621640FAE6ED34967E0EB6F7BEFDE8B\#: :text=Published\%20for\%20Joint\%20Commission\%20accredited,risk\%20and\%20prevent\%20f

\section{Figures}


Figure1. Age of patient involved in medication error

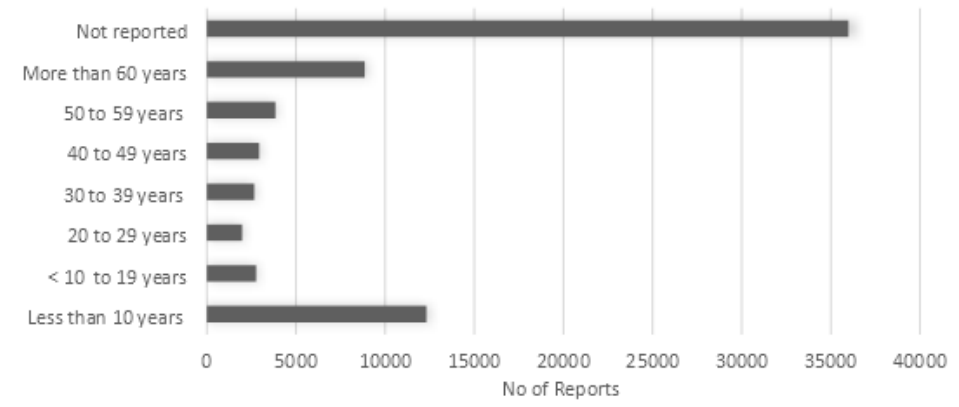

Figure 1

Age of patient involved in medication error

Figure2. Source and detection of error by staff

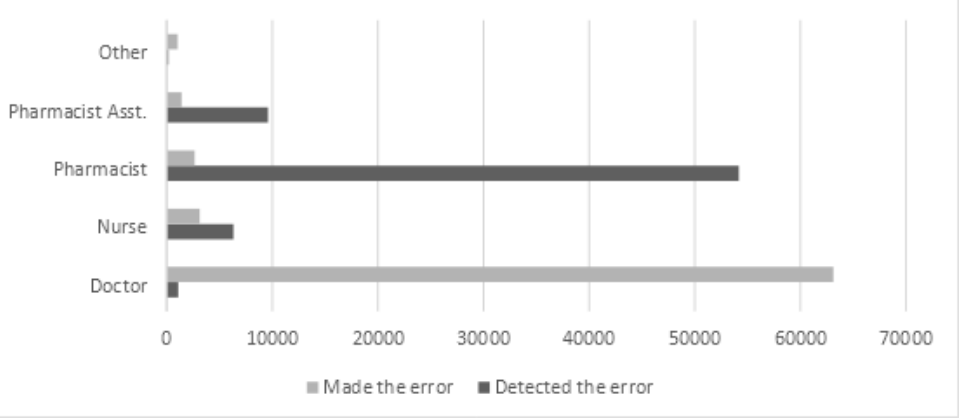

Figure 2

Source and detection of error by staff 